\title{
A LEITURA DE LITERATURA SUL-RIO-GRANDENSE CONTEMPORÂNEA NO CONTEXTO UNIVERSITÁRIO
}

\author{
Magali Lippert da Silva ALMEIDA \\ João Victor Martins CASTELLO \\ Júlia de Andrade GOMES
}

\section{RESUMO}

A questão que pretendemos responder neste artigo é se a literatura sul-rio-grandense contemporânea é lida pelos leitores gaúchos. Para isso, foram analisadas e discutidas as respostas a um questionário que visava delimitar o horizonte de leitura do entrevistado, verificando sua familiaridade com a literatura gaúcha contemporânea. O questionário foi aplicado, aleatoriamente, no Campus do Vale, da Universidade Federal do Rio Grande do Sul. Observa-se, nas respostas ao instrumento de coleta de dados, a presença majoritária de best-sellers e cânones internacionais entre as leituras feitas pelos participantes e pouca presença da literatura sul-rio-grandense publicada atualmente. Disso conclui-se que o mercado literário internacional vem ofuscando expressões literárias locais no Estado, e que, cada vez mais, há um afastamento entre obra gaúcha e leitor gaúcho.

PALAVRAS-CHAVE: Literatura sul-rio-grandense; Literatura e Mercado; Literatura e Sociedade.

\section{THE CONTEMPORARY LITERATURE OF RIO GRANDE DO SUL'S READING IN THE UNIVERSITARY CONTEXT}

\section{ABSTRACT}

The question we intend to answer in this article is whether contemporary Rio Grande do Sul literature is read by Rio Grande do Sul readers. For this, the answers to a questionnaire that aimed to delimit the interviewee's reading horizon were analyzed and discussed, verifying their familiarity with the contemporary gaucho literature. The questionnaire was randomly applied at the Campus do Vale, of the Federal University of Rio Grande do Sul. In the responses to the data collection instrument, a majority of international bestsellers and canons was observed among the participants' readings, and little presence of the Rio Grande do Sul literature currently published. From this it can be concluded that the international literary market has been obfuscating local literary expressions in the state, and that, increasingly, there is a gap between gaucho books and gaucho readers.

KEYWORDS: South-rio-grandense literature; Literature and Market; Literature and Society.

\section{LA LECTURE DE LITTÉRATURE DU RIO GRANDE DO SUL DANS LE CONTEXTE UNIVERSITAIRE}

\section{RESUMÉ}

La question à laquelle nous entendons répondre dans cet article est de savoir si la littérature contemporaine du Rio Grande do Sul est lue par les lecteurs du Rio Grande do Sul. Pour cela, les réponses à un questionnaire visant à délimiter l'horizon de lecture de la personne interrogée ont été analysées et discutées, vérifiant ainsi leur familiarité avec la littérature gaucha contemporaine. Le questionnaire a été appliqué de manière aléatoire au Campus do Vale, de la Université Fédérale du Rio Grande do Sul. Dans les réponses à l'instrument de collecte de données, une majorité des best-sellers et des canons internationaux ont été observés parmi les lectures des participants, et peu de littérature actuellement publiée sur le Rio Grande do Sul. On peut en conclure que le marché littéraire international a occulté les expressions littéraires locales dans l'État et qu'il existe de plus en plus de fossé entre les livres gauchos et le lecteur gaucho.

MOTS-CLÉS: Littérature du Rio Grande do Sul; Littérature et marché; Littérature et société.

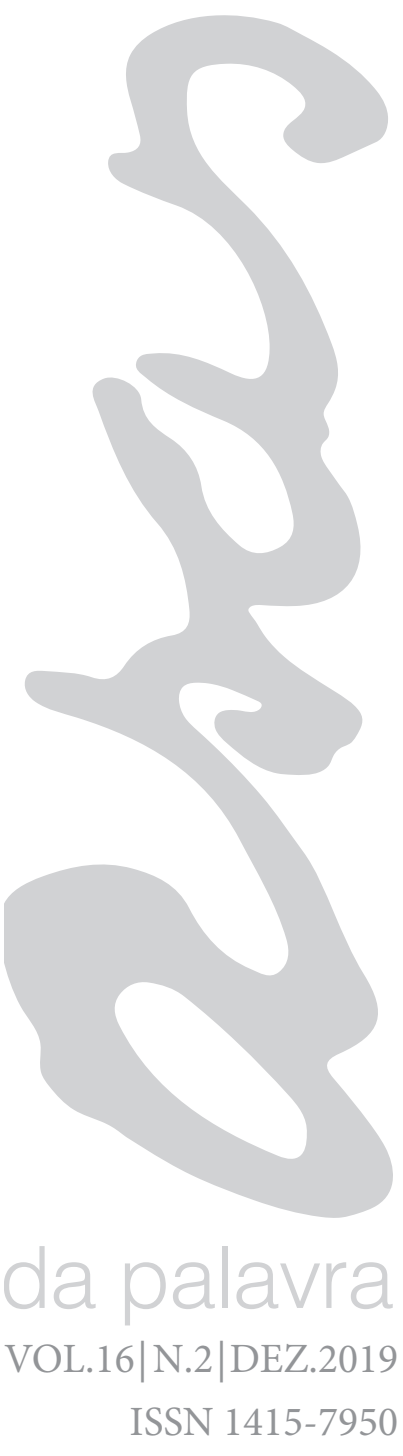




\section{INTRODUÇÃO}

Em 2015, quando lançou seu livro de contos Ensaio sobre o não e outros fracassos, o escritor e professor gaúcho Marcelo Rocha disse, no conto Se o leitor em uma noite solitária... : "Você deve ter ganhado o novo livro de contos do Marcelo Rocha, 'Ensaio sobre o não e outros fracassos'. Provavelmente é amigo ou familiar do autor" (ROCHA, 2015, p. 73).

Foi assim, provocados por essa ironia do autor e professor gaúcho acerca da sua própria produção literária que os pesquisadores Magali Lippert, Marlon de Almeida e Lizandra Brasil Estabel decidiram, em 2016, se dedicar a demanda de leitura de textos escritos por escritores gaúchos em atividade. Será realidade que os autores que publicam atualmente no Estado são lidos apenas por amigos e familiares? Para onde escoa a produção de impressos? Como é constituído nosso sistema literário? O estudo aqui apresentado faz parte dessas inquietações e tenta responder parte delas.

Para que chegássemos nesse estágio do estudo foi necessário o mapeamento produzido pelos pesquisadores citados acima, com o auxílio de seus bolsistas, que levantou, minuciosamente, todos os nomes de escritores que publicaram no Rio Grande do Sul entre 1976 e 2016; ou seja, da data de elaboração do projeto, os últimos quarenta anos (o mapeamento começou em 2017). O período escolhido se deu por haver um vazio nos estudos teóricos exploratórios sobre a época, além de coincidir com a popularização do ISBN (International Standard Book Number), que ao ser oficializado como norma internacional em 1972, facilitou a busca pelos escritores. Também por ser um período de reabertura política que desencadearia uma propensão maior a publicação sem medo de perseguições.

Munidos do mapeamento que identificou 939 escritores, bem como os subgêneros literários aos quais se dedicam/dedicaram, chegamos ao projeto atual, "O Consumo da Literatura Sul-Rio-Grandense Contemporânea por Leitores Gaúchos", em que os pesquisadores têm se dedicado a análise dos dados e aplicação de instrumentos de coleta de dados, buscando coletar informações sobre a leitura de literatura sulrio-grandense contemporânea por diferentes públicos do estado do Rio Grande do Sul.

Neste trabalho apresentaremos os dados coletados a partir da aplicação aleatória de 50 questionários no Campus do Vale da 
REVISTA DO PROGRAMA DE PÓS-GRADUAÇÃO EM COMUNICAÇÃO, LINGUAGENS E CULTURA DA UNIVERSIDADE DA AMAZÔNIA

Universidade Federal do Rio Grande do Sul. O objetivo da ferramenta de coleta de dados foi traçar os hábitos de leitura do universitário sul-rio-grandense, que enquanto tal, representa neste estudo o leitor sul-rio-grandense, por motivos detalhados na metodologia

Discutiremos, nos capítulos seguintes: (1) o motivo que nos levou a escolher o estudante universitário como amostragem, bem como a seleção de questões para o questionário, dentro das especificações da metodologia utilizada na pesquisa; (2) a análise, com o auxílio de gráficos, dos resultados, ressaltando aqueles que possam indicar uma tendência de interesses de leitura dos entrevistados; (3) o levantamento de causas da realidade indicada pelos resultados, com base em leituras sobre Literatura e Sociedade, Mercado Literário e Indústria Cultural; (4) a conclusão: tentando definir o lugar do leitor no sistema literário contemporâneo gaúcho, assim como o futuro deste sistema a partir dos resultados obtidos.

\section{METODOLOGIA}

A escolha pelos estudantes universitários para este estudo se deve ao fato de que, como nos diz a pesquisa Retratos da Leitura no Brasil, de 2016, 82\% dos estudantes universitários se consideram leitores (FAILLA, 2016, p.187). Tal proporção não é tão significativa em nenhuma outra escolaridade no Brasil. Uma possível razão disso, somos levados a pensar, é a grande carga de leituras exigidas em um curso de formação acadêmica superior, entretanto, segundo a mesma pesquisa, apenas 7\% dos estudantes universitários entrevistados relataram que seu motivo principal para a leitura são as exigências da faculdade, contra $20 \%$ que disseram ser o simples gosto pela leitura e $28 \%$ que relataram ser para adquirir conhecimentos gerais ou atualização cultural.

Podemos supor, então, que a universidade atua como agregadora de leitores. Seria ingênuo pensar que, por isso, é uma representação fidedigna e realista do leitor dentro de um sistema literário regional. De qualquer forma talvez seja a mais ambiciosa amostragem, considerando que se não for os acadêmicos a lerem uma determinada literatura, quem mais seria? Então a forma mais eficiente de encontrar na realidade social a resposta para isso é ir aonde há mais leitores concentrados. E a universidade, por seu caráter de formação intelectual nos pareceu o local mais adequado para uma coleta. 
Selecionamos para amostragem o Campus do Vale da Universidade Federal do Rio Grande do Sul por acessibilidade e trabalhamos com a coleta aleatória, à medida que o único fator em comum dos entrevistados é ocuparem um lugar dentro da universidade. De resto, a pesquisa acabou por abranger estudantes das mais variadas áreas e níveis acadêmicos, gêneros, idades e proficiências de leitura.

Quanto ao instrumento de coleta de dados, o questionário foi pensado como uma maneira rápida e objetiva de colher respostas dos participantes, sem deixar de incluir questões de memória para ressaltar os autores que estivessem presentes no imaginário universitário. Foram respondidos, no total, 50 questionários.

\section{RESULTADOS}

Do total de 50 questionários respondidos, 14 não conseguiram citar o nome de algum escritor gaúcho contemporâneo. Para as últimas perguntas, então, o total de respondentes se torna 36. Em idade, temos uma maioria de jovens e jovens adultos entre 18 e 25 anos, com quarenta incidências, mas há presença também de adultos de até 53 anos, com uma incidência e em torno de 30 anos, com nove incidências.

\section{Idade}

50 respostas

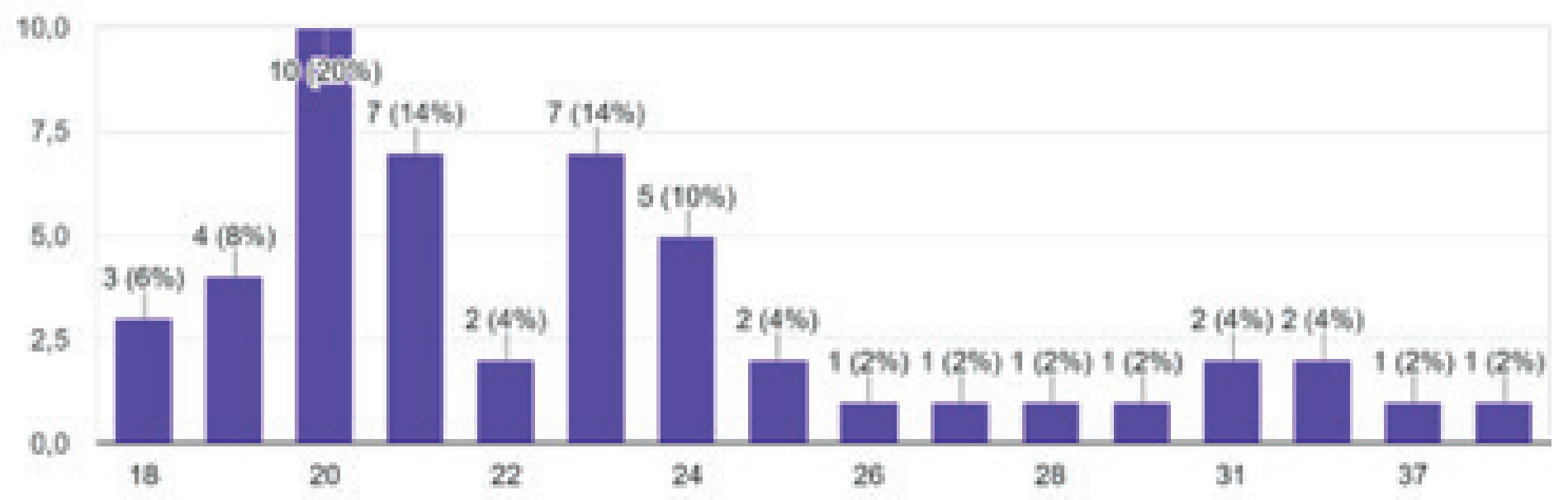


Há uma leve predominância do sexo masculino nas respostas ao questionário.

\section{Sexo}

50 respostas

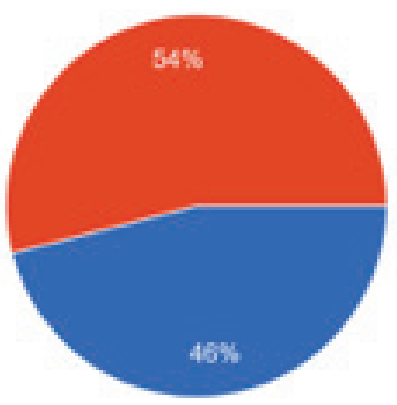

Quanto aos cursos dos respondentes, houve predominância de Letras, Geografia, História e Ciências Sociais, mas participaram também alunos de cursos como Matemática e Ciência da Computação. Quanto ao nível acadêmico, como esperado, houve maioria da graduação. Porém, houve participação tanto do Mestrado (Ciências Sociais e Geografia) quanto do Doutorado (Ciências Sociais e Letras).

Grau

50 respostas

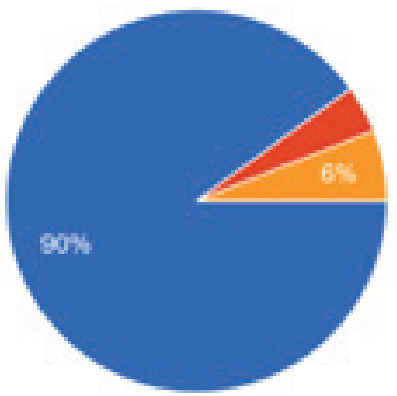


A quantia de participantes que se consideravam leitores foi significativa: $90 \%$.

\section{Você se considera leitor?}

50 respostas

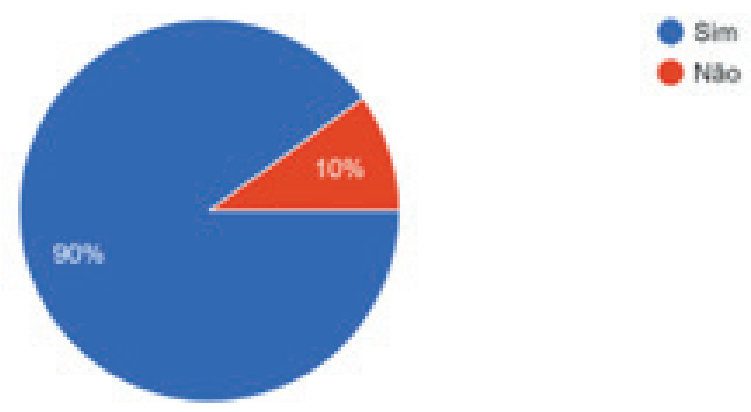

Mas há um decréscimo quanto à presença de leitores literários.

Você se considera um leitor literário?

50 respostas

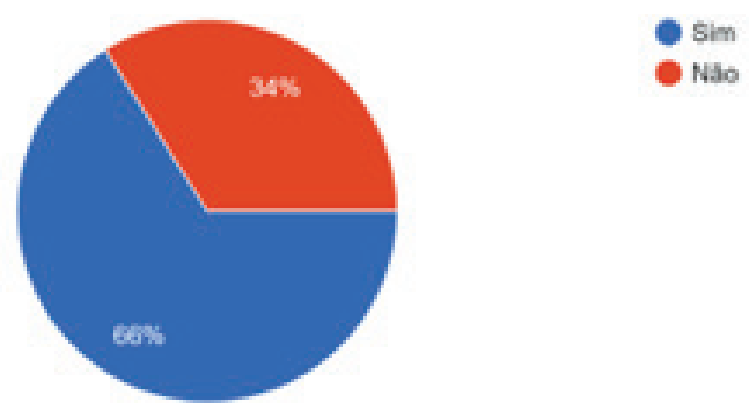

Quanto ao consumo de literatura contemporânea (entrando aí tanto livros nacionais quanto internacionais), há uma maioria de leitores, com $62 \%$ dos respondentes afirmando que costumam ler literatura produzida atualmente.

Você costuma ler livros de literatura contemporânea?

50 respostas

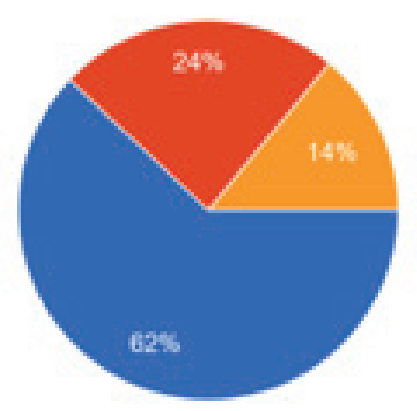


Porém, houve um descréscimo significativo de leitores ao direcionar-se a pergunta para o regional. Apenas 10\% afirmaram também ler literatura produzida atualmente dentro do Rio Grande do Sul.

\section{Você costuma ler literatura contemporânea de escritores gaúchos?}

\section{0 respostas}
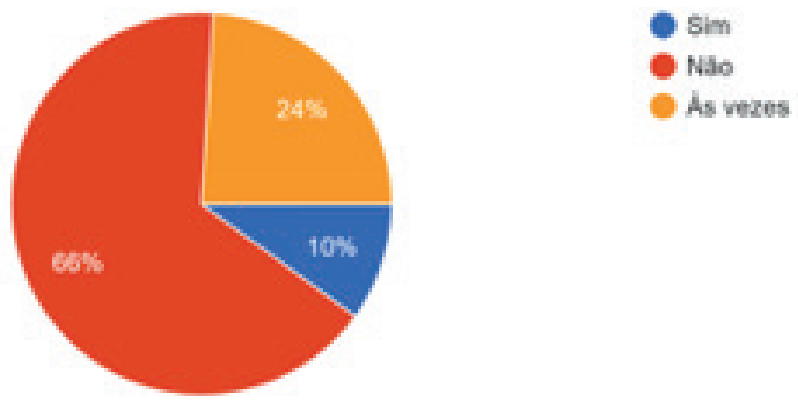

Além das perguntas já aqui apresentadas, houveram outras quatro voltadas a traçar o perfil leitor dos participantes, assim como o imaginário quanto aos autores contemporâneos gaúchos. As perguntas 3 (Cite o título do livro que você está lendo ou do que você leu mais recentemente) e 4 (Cite os 3 melhores livros que você já leu) não receberão gráfico correspondente devido ao número excessivo de respostas diferentes, todavia, exibiremos em seguida os autores e livros que foram citados:

$\mathrm{Na}$ pergunta 3: tivemos muitos participantes lendo, no momento da aplicação do questionário, livros teóricos, como Veias Abertas da América Latina, de Eduardo Galeano, Raízes do Brasil, de Sérgio Buarque de Holanda, A Natureza do Espaço, de Milton Santos e O Homem e Seus Símbolos, de Carl Jung. Porém houve, também, um número significativo de leituras de obras canônicas e best-sellers. Apareceram tanto O Processo, de Franz Kafka, e Madame Bovary, de Gustave Flaubert, quanto Não Conte a Ninguém, de Harlan Coben, e Deuses Americanos, de Neil Gaiman.

$\mathrm{Na}$ pergunta 4: um grande favorito de nossos participantes foi George Orwell, que apareceu tanto com A Revolução dos Bichos quanto com 1984. Outros que marcaram presença foram Gabriel Garcia Marquez, com Cem Anos de Solidão, Fiódor Dostoiévski, com Notas do Subsolo e Os Irmãos Karamázov, Tolkien, com O Silmarillion 
e $O$ Senhor dos Aneís, e tímido, mas presente, Érico Veríssimo, com $O$ Retrato (segundo volume da trilogia O Tempo e o Vento). Porém, os verdadeiros protagonistas em aparições foram os best-sellers, que apareceram 33 vezes, com livros como $O$ Último Olimpiano, de Rick Riordan, O Pequeno Príncipe, de Antoine de Saint-Éxupery, A Menina que Roubava Livros, de Markus Zusak, As Crônicas de Gelo e Fogo, de George R.R. Martin, a série Harry Potter, de J.K. Rowling, entre muitos outros.

Por fim, quanto à citação de autores gaúchos para traçar o imaginário universitário, tivemos número significativo de respondentes que não puderam citar um único escritor(a) gaúcho contemporâneo, com 14 de 50 incidências. Além disso, 13 respondentes foram capazes de citar apenas um escritor(a), 3 citaram dois escritores, 9 citaram três escritores, 7 citaram quatro escritores e apenas 4 citaram cinco escritores.

\section{Citaçōes de autores gaúchos}

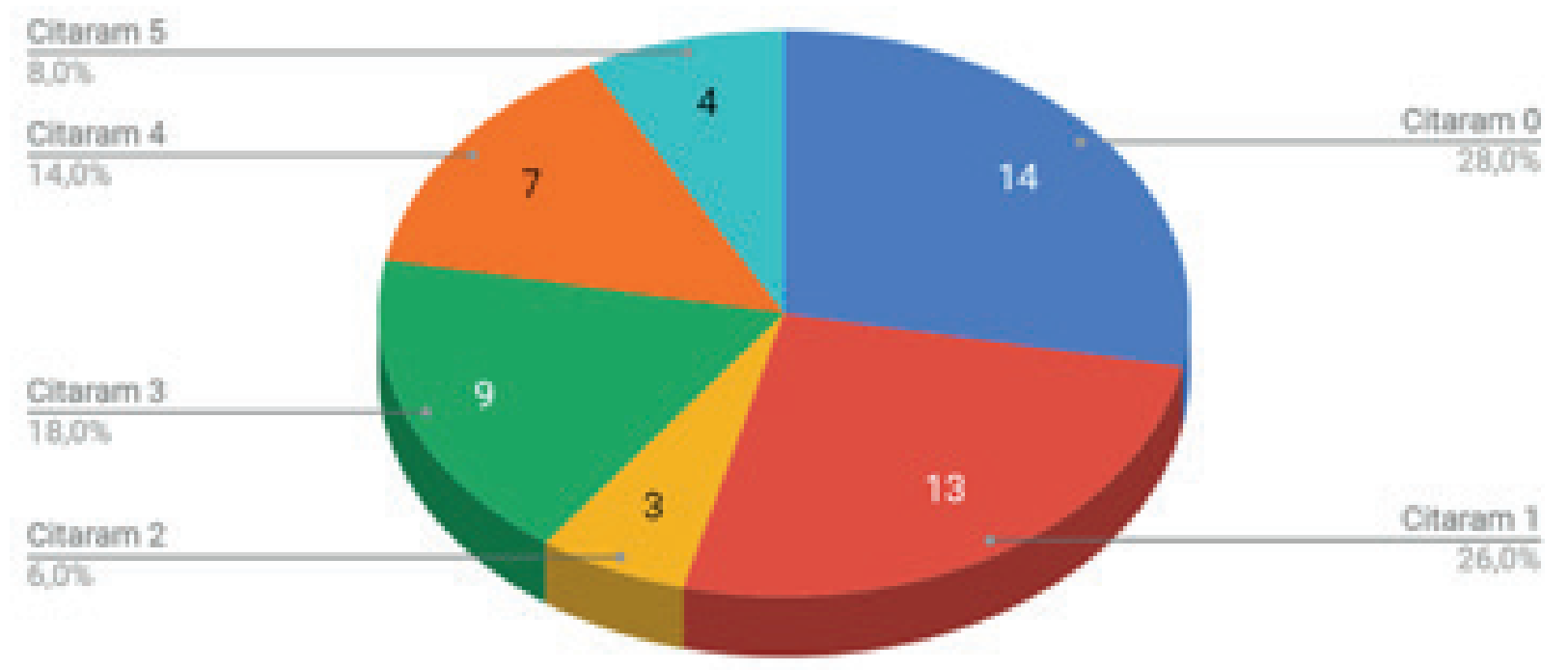


Quanto à efetiva leitura desses escritores citados, observamos que aqueles respondentes que citaram apenas 1 autor, em maioria (65\%), leram o autor que citaram. Contudo, à medida que chegamos aqueles que conseguiram citar mais autores, observa-se que nem todos leram o que citaram $(25 \%)$.

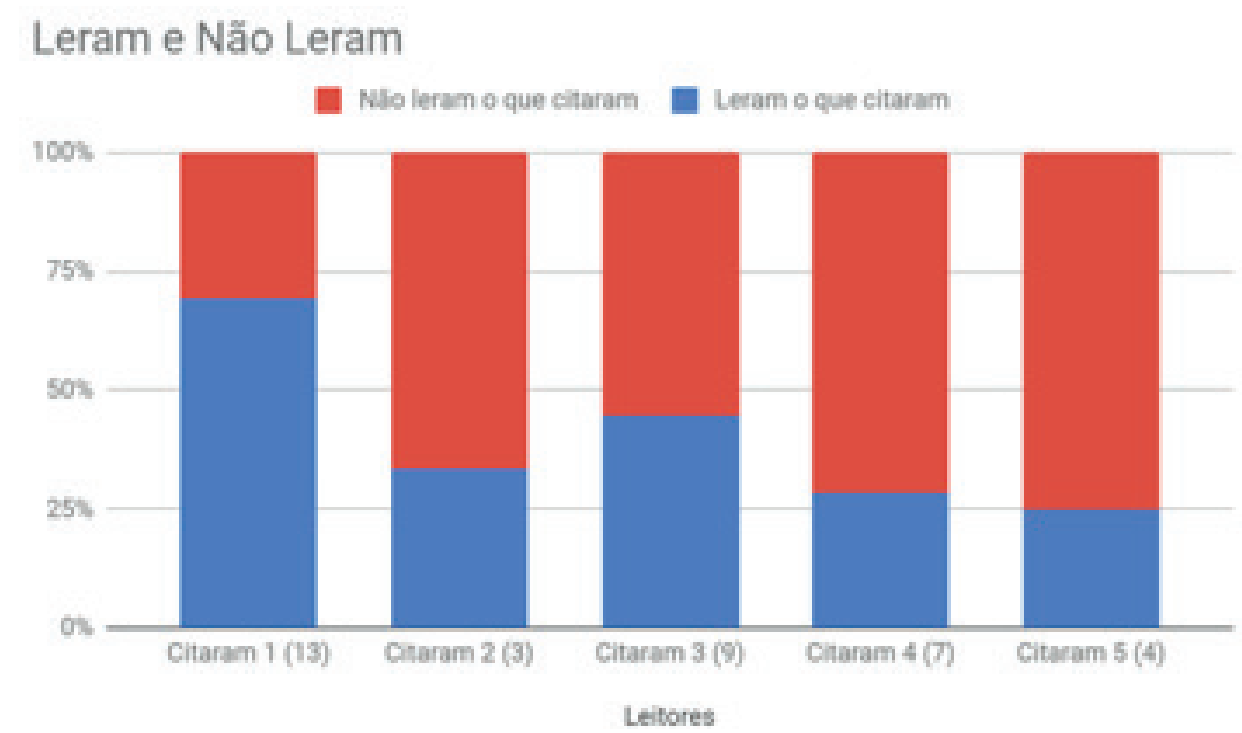

Quanto aos autores que tiveram maior destaque, podemos notar que Luis Fernando Veríssimo foi muito lembrado e lido, com 13 citações e 12 leituras. Uma popularidade tão grande quem sabe explique-se pela sua influência jornalística, propulsão ao centro do país por conta do sucesso de Analista de Bagé nos anos 80 e pela proximidade com outro celebríssimo escritor sul-rio-grandense: Érico Veríssimo, seu pai. Além dele, Moacyr Scliar, Caio Fernando Abreu e Sérgio Faraco encabeçaram os resultados da coleta de dados. Isto, talvez, deva-se ao fato de que estes autores foram leitura obrigatória no vestibular da UFRGS nos últimos cinco anos, o que em si já é um índice de prestígio. Ademais, nota-se uma tímida presença da juventude literária do circuito sul-rio-grandense, com nomes como os de Angélica Freitas, Daniel Galera e Natália Borges Polesso. Também Assis Brasil, Lya Luft, Mário Quintana e Tabajara Ruas obtiveram aparição significante, porém, aquilo que definiu, ao analisarem-se os dados, as citações e leituras de um escritor(a) foi o prestígio que este possui dentro do sistema literário sul-rio-grandense, seja por meio jornalístico, de sobrenome ou de indicação como leitura obrigatória no vestibular da maior universidade do Estado. 


\section{QUANTO À ESCASSA LEITURA DE AUTORES SUL-RIO- GRANDENSES}

Agora, falando sobre leitura em geral e não apenas de escritores gaúchos, ao traçarmos o perfil leitor dos participantes com as perguntas 3 e 4 do questionário, foi possível notar alguns aspectos interessantes: na pergunta 3 , em que pedíamos para que os participantes citassem o título do livro que estavam lendo ou o título do livro que leram mais recentemente, 38 dos 50 entrevistados citaram obras internacionais. Destes, 13 são best-sellers. Na pergunta seguinte, que pedia para que eles citassem os 3 melhores livros que já leram, 33 obras citadas, de um total de 49, são best-sellers. 3 obras citadas são de autores sul-riograndenses, entretanto, são obras que foram escolhidas como leitura obrigatória do vestibular da UFRGS nos últimos cinco anos. Assim, fica claro a escassa leitura de autores sul-rio-grandenses por leitores gaúchos no panorama geral da coleta de dados.

Em A Literatura e o Leitor, Luiz Costa Lima levanta o seguinte questionamento:

Como, por exemplo, se estabelece o consenso sobre
a excelência de um autor? Seria por que o horizonte
de expectativas dos leitores se ajusta com o horizonte
possibilitado pelo texto, numa espécie de contrato
natural, ou por que instâncias de poder específico - isto é,
do poder literário - se não mesmo as inclinações políticas
da sociedade se manifestam e/ou orientam em favor da
concessão daquele prêmio?" (LIMA, 2002, p.44)

Podemos, também, fazer essas perguntas aplicadas à Literatura sul-rio-grandense. Os autores sul-rio-grandenses não são lidos pelo público geral, como nossa pesquisa demonstra, seria isto por que a Literatura sul-rio-grandense não tem prestígio dentro das instâncias do poder literário? Ou, então, o horizonte de expectativa dos leitores é marcado e influenciado pela mídia, gerando, assim, um horizonte de expectativas delimitado pelo Mass Media?

Nas perguntas 7 e 8 fica claro que os autores sul-rio-grandenses conhecidos e lidos pelos participantes da pesquisa são autores presentes nos meios de comunicação ou que já são canonicamente aceitos pelas instâncias do poder literário: Luís Fernando Veríssimo, Moacyr Scliar, Sérgio Faraco e Caio Fernando Abreu foram os autores gaúchos mais citados na pergunta 7. Já na pergunta 8 , os autores mais lidos pelos participantes foram: Luís Fernando Veríssimo, Caio Fernando Abreu, 
David Coimbra não é nem foi leitura obrigatória da UFRGS. David Coimbra pode ser considerado um autor de literatura voltado às massas, sendo seus meios de circulação o jornal Zero Hora e a rádio Gaúcha.

É sabido que a literatura de massa está ligada à nossa sociedade de consumo e, logo, os meios de comunicação influenciam nesta dinâmica. Gláucio Aranha e Fernanda Batista (2009) falam disso em seu artigo Literatura de Massa e Mercado:

\begin{abstract}
Por ser um produto dirigido às massas, de grande penetração, esta literatura sofre influência direta dos fatores de mercado, tendo sido estimulada pelo incremento da capacidade de reprodução e distribuição dos bens culturais. Deste modo, pensar a lógica imanente a esta forma importa pensar a lógica comunicacional da mesma (reprodução/distribuição) como elemento relevante no processo de consolidação deste bem cultural. (ARANHA; BATISTA, 2009, p.2)
\end{abstract}

A literatura de massa, por sua vez, cria uma dinâmica em que o leitor é também consumidor, e o consumo delimita o que merece prestígio e o que não merece. Nesta lógica de consumo, os best-sellers acabam tornando-se as obras que mais merecem prestígio por serem as obras mais consumidas (compradas). E obras prestigiadas por outros meios, como as que são nomeadas para leitura obrigatória do vestibular, acabam, assim, tornando-se mesmo que momentaneamente, sucessos de venda. O conteúdo da obra nem sempre é levado em consideração, pois o prestígio do autor que vende e se "populariza" acaba conquistando uma legião de consumidores/leitores. Assim, a comunidade de leitores-consumidores passa
a desempenhar um importante papel de legitimação.
Os índices de venda ("campeões de venda", "os mais
vendidos") tomam a forma de indicadores de qualidade
e excelência para o grande público. Portanto, o fato
de ser mais vendido agrega valor ao bem ofertado.
(ARANHA; BATISTA, 2009, p.3)

Esta seria uma das hipóteses para explicar o motivo pelo qual a literatura sul-rio-grandense não é consumida no nosso próprio Estado. A maioria dos autores não são conhecidos do público geral e por não serem conhecidos, acabam, na maioria das vezes, por não serem lidos. Não tivemos tempo para avaliar a qualidade literária de todos os escritores gaúchos mapeados, mas percebemos que o número 
de bons escritores é muito superior àqueles citados pelos respondentes do questionário. Então a nova questão (e que trabalharemos em outros estudos) seria para onde escoa a produção dessas centenas de escritores que não possuem o privilégio de escreverem para veículos de comunicação e que não caíram "na graça" dos acadêmicos que ditam o que será lido nos vestibulares e, depois, nos cursos de graduação e pósgraduação?

A obra literária não é um objeto que exista por si só, sua existência só tem validade se ela for lida. Ela é criada pela dinâmica obra-leitor/ autor-leitor. Segundo Jauss (1982), a experiência primária de uma obra de arte realiza-se na sintonia com seu efeito estético no qual há uma compreensão fruidora e uma fruição compreensiva do leitor para com a obra. Sendo assim, a obra por si só não é suficiente sem a atividade leitora e fruição do leitor.

\begin{abstract}
A experiência estética não se inicia pela compreensão e interpretação do significado de uma obra; menos ainda pela reconstrução da intenção de seu autor. A experiência primária de uma obra de arte realiza-se na sintonia com seu efeito estético, isto é, na compreensão fruidora e na fruição compreensiva. (LIMA, 2002, p.69)
\end{abstract}

Para pensar sobre isto, valem alguns apontamentos: o mapeamento feito pelos pesquisadores em 2016 levantou 939 escritores e escritoras gaúchos que publicaram no Estado entre os anos de 1976 e 2016. Nesta coleta de dados apenas 16 nomes foram lembrados. Se a Literatura efetivamente realiza-se no ato de leitura, como Jauss (1982) teoriza, então qual é o real tamanho e abrangência da literatura sul-riograndense?

\title{
CONCLUSÃO
}

Através da nossa pesquisa e de sua natureza exploratória optamos pela coleta de dados através de um questionário. Pudemos notar a pouca leitura de literatura sul-rio-grandense contemporânea do público universitário do Estado. De um público que se diz leitor, apenas $10 \%$ afirma ser leitor de literatura contemporânea sul-rio-grandense. Este é um dado preocupante, uma vez que demonstra a escassez de leitores que sustente um mercado literário de autores em atividade.

A literatura sul-rio-grandense não está presente no horizonte de expectativas dos leitores-consumidores, talvez pelo fato da imensa 
de um modo geral, ou talvez pela escrita muitas vezes não convidativa para um público ou, ainda, e mais provável: pela falta de espírito de curiosidade, investigação e abertura a ler autores que são "santos de casa", como se esses autores fossem inferiores aos estadunidenses ou europeus. O que percebemos é que as pessoas tendem a ler aquilo que as outras estão lendo ou leram recentemente. Em Biblioteconomia diz-se que apenas $20 \%$ de um acervo realmente circula e que os outros $80 \%$ raramente saem das estantes, os bibliotecários fazem essa afirmação com base no Princípio de Pareto e a Lei do 80/20, o que significa que "uso passado é sinônimo de uso futuro".

\begin{abstract}
A literatura biblioteconômica, inclusive em língua portuguesa, é bastante generosa em estudos deste tipo, alguns bastante complexos e aprofundados, outros apenas superficiais. Todos eles parecem partir da premissa - ou da esperança - de que o uso passado irá repetir-se no futuro e que o bibliotecário, ao ter acesso a esses dados de uso passado poderá prepararse, convenientemente para dar atendimento ao futuro próximo. (VERGUEIRO, p. 89-90, 1989)
\end{abstract}

Se a literatura sul-rio-grandense não circula, se ela não é lida, seu uso futuro estará condenado, a menos que algo seja feito.

Dos escritores gaúchos mais lidos e conhecidos do público entrevistado estão, em maior parte, leituras que foram as obrigatórias para o vestibular da Universidade Federal do Rio Grande do Sul. Já era esperado que eles aparecessem - já que a coleta de dados foi feita dentro de um Campus da UFRGS e com estudantes universitários entretanto, o preocupante é que apenas um outro autor tenha sido um dos mais citados. Podemos considerar, então, que as universidades possuem certo poder no contexto literário pois ditam o que deve ser lido, obrigando ao "uso" (obrigatoriedade para o vestibular) que se tornará "uso futuro", daí o poder de canonizar certos autores.

Sendo assim, podemos notar que os escritores ainda têm muito o que enfrentar para que suas obras sejam lidas. Se nem o público universitário que se considera leitor é capaz de fazer leituras de obras de autores gaúchos, quem dirá o público geral. Os autores gaúchos continuam, infelizmente, sendo lidos por "familiares e amigos do autor", como ironiza Marcelo Rocha em Ensaio sobre o não e outros fracassos. A consciência de que vivemos este cenário na literatura do Rio Grande do Sul é o primeiro passo para que trabalhemos em uma mudança efetiva na forma de divulgação e acesso a Literatura 
aqui produzida. O que acarretaria, também, numa mudança nas representações sociais não só culturais e artísticas, mas também de nosso povo e de nossa terra.

\section{REFERÊNCIAS}

ARANHA, Gláucio; BATISTA, Fernanda. Literatura de massa e mercado. Revista Contracampo, n. 20, p. 121-131, 2009. Disponível em: http://periodicos.uff.br/ contracampo/article/view/17183. Acesso em 21 de outubro de 2019.

FAILLA, Zoara (org.). Retratos da Leitura no Brasil. Rio de Janeiro: Gtm Editores, 2016.

JAUSS, Hans. Robert. Toward an aesthetic of reception. Minneapolis: University of Minnesota Press, 1982.

LIMA, Luis Costa et al. A literatura e o leitor: textos de estética da recepcão. $2^{\mathrm{a}}$ ed., rev.ampliada ed. Rio de Janeiro: Paz e Terra, 2002.

VERGUEIRO, Waldomiro. Desenvolvimento de Coleções. São Paulo: Pólis, 1989.

Bacharel em Biblioteconomia (UFRGS), Mestre em Comunicação e Informação (UFRGS) e Doutora em Letras/Estudos Literários (UFRGS). Professora do IFRS/Campus Porto Alegre e pesquisadora do grupo LEIA (UFRGS/IFRS). Atualmente é coordenadora do curso Técnico em Biblioteconomia do IFRS. E-mail: magali.lippert@poa.ifrs.edu.br.

João Victor Martins CASTELLO

Graduando em Letras pela Universidade Federal do Rio Grande do Sul. Atualmente, atua como pesquisador bolsista FAPERGS pelo Instituto Federal de Educação, Ciência e Tecnologia do Rio Grande do Sul, sob orientação da professora Magali Lippert da Silva Almeida, no grupo de pesquisa LEIA (UFRGS/IFRS). E-mail: joaovmcastello@gmail.com.

Júlia de Andrade GOMES

Graduanda em Letras pela Universidade Federal do Rio Grande do Sul. Foi bolsista PIBIC-CNPq de agosto de 2018 até julho de 2019 pela Universidade Federal do Rio Grande do Sul. E-mail: hearjuliaroar@gmail.com 